\title{
Visceral Adipose Tissue and Skeletal Muscle Index Distribution Predicts Severe Pancreatic Fistula Development After Pancreaticoduodenectomy
}

\author{
HIROAKI YAMANE ${ }^{1}$, TOMOYUKI ABE ${ }^{1}$, HIRONOBU AMANO ${ }^{1,2}$, KEIJI HANADA ${ }^{3}$, \\ TOMOYUKI MINAMI ${ }^{3}$, TSUYOSHI KOBAYASHI ${ }^{2}$, TOSHIKATSU FUKUDA ${ }^{4}$, \\ SHUJI YONEHARA ${ }^{5}$, MASAHIRO NAKAHARA ${ }^{1}$, HIDEKI OHDAN ${ }^{2}$ and TOSHIO NORIYUKI ${ }^{1,2}$ \\ ${ }^{1}$ Department of Surgery, ${ }^{3}$ Department of Gastroenterology, \\ ${ }^{5}$ Department of Pathology, Onomichi General Hospital, Onomichi, Japan; \\ ${ }^{2}$ Department of Gastroenterological and Transplant Surgery, Applied Life Sciences, \\ Institute of Biomedical and Health Sciences, Hiroshima University, Hiroshima, Japan; \\ ${ }^{4}$ Department of Surgery, Hiroshima General Hospital of West Japan Railway Company, Hiroshima, Japan
}

\begin{abstract}
Background/Aim: In this study, we investigated the effect of body composition on pancreatic fistula $(P F)$ development after pancreaticoduodenectomy $(P D)$. Materials and Methods: All consecutive patients with pancreatic and extrahepatic biliary malignancy following $P D$ who were treated between 2006 and 2016 were enrolled. Results: PF developed in $30.3 \%$ of cases (30/99 patients), including a grade $B$ PF in $25.3 \%$ of cases (25/99 patients) and a grade $C P F$ in $5.1 \%$ of cases (5/99 patients). Univariate analysis identified that body mass index $\geq 25 \mathrm{~kg} / \mathrm{m}^{2}$, visceral adipose tissue area (VATA)/skeletal muscle index (SMI) $\geq 2.0$, pancreatic duct diameter $\leq 3 \mathrm{~mm}$, and drain amylase concentration (Amy) on postoperative day (POD) $1 \geq 5000$ $U / L$ were significantly associated with $P F$ (grade $B, C)$ after $P D$. Multivariate analysis indicated that VATA/SMI $\geq 2.0$ $(p=0.009)$, pancreatic duct diameter $\leq 3 \mathrm{~mm}(p=0.003)$, and drain Amy on PODI $\geq 5000$ U/L $(p=0.032)$ were independent risk factors for PF. Conclusion: Elevated VATA/SMI was the only preoperative key factor for $P F$ after $P D$.
\end{abstract}

Pancreas head malignancies and extrahepatic biliary duct have dismal prognoses, even after curative resection, and often require pancreaticoduodenectomy (PD). Improvements in surgical techniques and perioperative management have

Correspondence to: Tomoyuki Abe, Department of Surgery, Onomichi General Hospital, Onomichi, Hiroshima, 722-8508, Japan. Tel: +81 848228111, Fax: +81 848233214, e-mail: t.abe.hiroshima@gmail.com

Key Words: Skeletal muscle index, pancreaticoduodenectomy, pancreatic fistula, visceral adipose tissue area. dramatically reduced the rates of morbidity and mortality after PD, which are reported as $15.3-44.2 \%$ and $0.6-4.3 \%$, respectively (1-4).

However, these results are still dismal among patients undergoing gastrointestinal surgery. Pancreatic fistula (PF) development is among the most concerning of PD complications as it can result in massive bleeding following the formation of pseudo-aneurysm ruptures and refractory abdominal abscesses. A 2005 International Study Group on Pancreatic Fistula (ISGPF) defined PF (5) and documented its occurrence as being approximately $17.9 \%-30.2 \%(2,6-8)$.

Recently, sarcopenia, which is defined as a decreased amount of skeletal muscle, was shown to adversely affect prognosis after surgical resection in various cancer types (912). Kaido et al. reported that patients with sarcopenia were susceptible to postoperative infectious complications compared with non-sarcopenia patients among liver transplant recipients (12). Previous studies have demonstrated that anthropomorphic factors negatively affect postoperative complications $(13,14)$. However, the mechanism by which anthropomorphic factors influence postoperative outcomes after PD and the development of PF remain unclear. We created a new evaluation system by combining visceral adipose tissue area (VATA) and skeletal muscle index (SMI) imbalance, and used this system to identify patients with severe obesity and sarcopenia. The definition of sarcopenia and obesity differs among countries; thus, a new VATA/SMI evaluation system could be used to standardize these assessments.

To date, several variables, including postoperative drain amylase (Amy), main pancreatic duct diameter, remnant pancreas volume, pancreatic texture, and malnutrition status, were reported to be risk factors for PF development after PD 
$(2,3,8,15)$. In this study, we identified the clinicopathological variables, including anthropomorphic factors, evaluated using preoperative computed tomography $(\mathrm{CT})$, that are associated with PF development.

\section{Materials and Methods}

Patients. Patients who underwent PD between 2006 and 2016 were identified from the Onomichi General Hospital Department of Surgery, retrospectively. We included patients who developed pancreatic ductal adenocarcinoma, adenocarcinoma of the papilla, extrahepatic cholangiocarcinoma, and intraductal papillarymucinous carcinoma. The study was approved by the local Institutional Review Board and written informed consent was obtained from all patients (OJH-201642).

Preoperative CT analysis of anthropomorphic composition. Eight weeks prior to operation, all patients underwent a preoperative nonenhanced and enhanced multidetector CT (DISCOVERY CT750 HD; GE Healthcare, Waukesha, WI, USA and Sensation 16; Siemens, Forchheim, Germany, respectively) with a section thickness of $2.5-5 \mathrm{~mm}$. The CT images at the third lumbar vertebra (L3) were analysed using Advantage Workshop 4.5 (GE Healthcare, Waukesha, WI, USA) and Virtual Place Fujin (AZE Ltd., Tokyo, Japan) (11). Body composition assessment included VATA, subcutaneous adipose tissue area (SATA), and skeletal muscle area. $\mathrm{CT}$ analysis was performed by trained investigators (H.Y. and T.A.), who were blinded to patient characteristics and clinical outcomes. Tissue Hounsfield unit (HU) thresholds were employed as follows: -29 to $150 \mathrm{HU}$ for skeletal muscle area, -190 to -30 for SATA, and -150 to -50 for VATA (16). Skeletal muscle area was defined at the L3 level and included the psoas major and minor, paraspinal muscles, and abdominal wall muscles. Skeletal muscle area was normalized for height in meters squared $\left(\mathrm{m}^{2}\right)$ to create the SMI. In our study, a VATA/SMI $\geq 2.0$ was defined as high and a VATA/SMI $<2.0$ was defined as low.

Definition of sarcopenia and pancreatic fistula. Sarcopenia was defined as a SMI $<43 \mathrm{~cm}^{2} / \mathrm{m}^{2}$ with a BMI $<25 \mathrm{~kg} / \mathrm{m}^{2}$ for males, a SMI $<53 \mathrm{~cm}^{2} / \mathrm{m}^{2}$ with a BMI $\geq 25 \mathrm{~kg} / \mathrm{m}^{2}$ for males and a SMI $<41 \mathrm{~cm}^{2} / \mathrm{m}^{2}$ for females (17). PF development was defined using the ISGPF (5). In this study, our definition of PF development as grades B and C was according to the ISGPF.

Ethical approval. All procedures performed in studies involving human participants were in accordance with the ethical standards of the institutional and/or national research committee and with the 1964 Helsinki declaration and its later amendments or comparable ethical standards.

Statistical analysis. Continuous variables were reported at the median and were analysed using the non-parametric Mann-Whitney $U$-test. Categorical variables were compared using the Fisher's exact test. The logistic regression analysis was performed to determine the associations between clinicopathologic factors and development of PF. Statistically significant variables on univariate analysis were entered into a multivariate logistic analysis. Differences between the results of comparative tests were considered significant according to a two-sided $p$-value of $<0.05$. Cut-off values for significant variables were employed according to the receiver operating characteristic curve. Calculations were performed using SPSS software (version 22; IBM Corp., Armonk, NY, USA).

\section{Results}

The overall mortality and morbidity rates in the 99 patients were $1.0 \%$ (1/99 patients) and 36.4\% (36/99 patients), respectively. PF developed in $30.3 \%$ of cases $(30 / 99$ patients), including a grade B PF in $25.3 \%$ of cases $(25 / 99$ patients) and a grade C PF in $5.1 \%$ of cases (5/99 patients). Nighty-nine patients who underwent PD were divided into two groups: the $\mathrm{PF}(\mathrm{N}=30,30.3 \%)$ and non-PF $(\mathrm{N}=69$, $69.7 \%$ ) groups. Patient demographics and univariate analyses are shown in Table I.

Risk factors for PF after PD. Univariate analysis indicated that obese patients (i.e., BMI $\geq 25 \mathrm{~kg} / \mathrm{m}^{2} ; p=0.032$ ) and patients with a high-VATA/SMI $(p=0.002)$, pancreatic duct diameter $\leq 3 \mathrm{~mm}(p<0.001)$ and drain Amy concentration $\geq 5000 \mathrm{U} / \mathrm{L}$ on POD1 $(p=0.002)$ were significantly at a higher risk of developing PF. Multivariate analyses identified that high-VATA/SMI (hazard ratio [HR], 5.353; 95\% confidence interval $[\mathrm{CI}]=1.534-18.680 ; p=0.009)$, pancreatic duct diameter $\leq 3 \mathrm{~mm}(\mathrm{HR}=6.580 ; 95 \% \mathrm{CI}=1.906-22.717$; $p=0.003)$ and drain Amy concentration $\geq 5000 \mathrm{U} / \mathrm{L}$ on POD1 $(\mathrm{HR}=4.910 ; 95 \% \mathrm{CI}=1.144-21.065 ; p=0.032)$ were the independent risk factors for PF (Table II).

Comparison of the characteristics between patients subdivided according to VATA/SMI. Clinicopathological variables for lowand high-VATA/SMI groups are shown in Table III. Patients with a high-VATA/SMI were more likely to be male $(p=0.001)$, have a higher BMI $(p<0.001)$, exhibit hypertension $(p=0.003)$, smoke more regularly $(p=0.013)$, and abuse alcohol $(p=0.001)$ more often than did patients with a lowVATA/SMI. The SMI level was equivalent between high- and low-VATA/SMI patients, whereas VATA was significantly higher in high-VATA/SMI patients $(p<0.001)$. SATA was much higher in high-VATA/SMI patients $(p<0.001)$. A longer operation time $(p=0.002)$ and increased intraoperative bleeding $(p=0.002)$ were seen in high-VATA/SMI patients. Notably, the postoperative complications were strongly associated with a high-VATA/SMI rather than a lowVATA/SMI $(p=0.001)$. PF development occurred in $14.9 \%$ (7/47 patients) of patients with a low-VATA/SMI and in $44.2 \%$ (23/52 patients) of patients with a high-VATA/SMI $(p=0.002)$.

\section{Discussion}

In this study, we identified that a high-VATA/SMI, pancreatic duct $\leq 3 \mathrm{~mm}$ and drain Amy concentration $\geq 5,000 \mathrm{U} / \mathrm{L}$ on POD1 were independently associated with PF development 
Table I. Univariate analysis of risk factors for pancreatic fistula development in patients who underwent pancreaticoduodenectomy.

\begin{tabular}{|c|c|c|c|c|}
\hline Variables & Overall (n=99) & Non-PF $(n=69)$ & $P F(n=30)$ & $p$-Value \\
\hline Age $\geq 70$ (years) & $55(55.6 \%)$ & $38(55.1 \%)$ & $17(56.7 \%)$ & 0.780 \\
\hline Sex, male & $69(69.7 \%)$ & $45(65.2 \%)$ & $24(80.0 \%)$ & 0.141 \\
\hline $\mathrm{BMI} \geq 25\left(\mathrm{~kg} / \mathrm{m}^{2}\right)$ & $20(20.2 \%)$ & $10(14.5 \%)$ & $10(33.3 \%)$ & 0.032 \\
\hline Diabetes mellitus & $24(24.2 \%)$ & $20(29.0 \%)$ & $4(13.3 \%)$ & 0.082 \\
\hline Hypertension & $49(49.5 \%)$ & $33(47.8 \%)$ & $16(53.3 \%)$ & 0.235 \\
\hline Tobacco usage & $53(53.5 \%)$ & $34(49.2 \%)$ & $19(63.3 \%)$ & 0.311 \\
\hline Alcohol abuse & $43(43.4 \%)$ & $28(40.6 \%)$ & $15(50.0 \%)$ & 0.526 \\
\hline Preoperative biliary drainage & $36(36.4 \%)$ & $26(37.7 \%)$ & $10(33.3 \%)$ & 0.601 \\
\hline Serum bilirubin $\geq 1.0(\mathrm{mg} / \mathrm{dl})$ & $41(41.4 \%)$ & $29(42.0 \%)$ & $12(40.0 \%)$ & 0.993 \\
\hline Serum albumin $\geq 3.5(\mathrm{mg} / \mathrm{dl})$ & $28(28.3 \%)$ & $23(33.3 \%)$ & $5(16.7 \%)$ & 0.091 \\
\hline Serum CRP $\geq 1.0(\mathrm{mg} / \mathrm{dl})$ & $18(18.2 \%)$ & $13(18.8 \%)$ & $5(16.7 \%)$ & 0.744 \\
\hline Sarcopenia & $40(40.4 \%)$ & $32(46.4 \%)$ & $8(26.7 \%)$ & 0.066 \\
\hline VATA/SMI $\geq 2.0$ & $52(52.5 \%)$ & $29(42.0 \%)$ & $23(76.7 \%)$ & 0.002 \\
\hline Operation time $\geq 500(\mathrm{~min})$ & $56(56.6 \%)$ & $37(53.6 \%)$ & $19(63.3 \%)$ & 0.475 \\
\hline Bleeding volume $\geq 700(\mathrm{ml})$ & $53(53.5 \%)$ & $38(55.1 \%)$ & $15(50.0 \%)$ & 0.748 \\
\hline Major vascular resection & $24(24.2 \%)$ & $20(29.0 \%)$ & $4(13.3 \%)$ & 0.526 \\
\hline Pancreatic duct diameter $\leq 3(\mathrm{~mm})$ & $33(33.3 \%)$ & $14(20.3 \%)$ & $19(63.3 \%)$ & $<0.001$ \\
\hline Pancreatic texture (soft) & $43(43.4 \%)$ & $23(33.3 \%)$ & $20(33.3 \%)$ & 0.002 \\
\hline Drain Amy on POD1 $\geq 5000(\mathrm{U} / \mathrm{L})$ & $21(21.2 \%)$ & $6(8.7 \%)$ & $15(50.0 \%)$ & $<0.001$ \\
\hline
\end{tabular}

Amy: Amylase; BMI: body mass index; CRP: C reactive protein; POD: postoperative day; SMI: skeletal muscle index; WBC: white blood cell; VATA: visceral adipose tissue area. Variables in bold are statistically significant $(p<0.05)$.

after PD. Previously, the VATA, soft pancreas, pancreatic duct $\leq 3 \mathrm{~mm}$, and an abnormal drain Amy concentration have been reported as risk factors for PF development after PD (5, $6,10,15,18)$. The ability to predict $P F$ occurrence by evaluating clinicopathological features in the clinical setting is beneficial to patients. Several studies have reported that sarcopenia is related to postoperative complications (12). In our study, sarcopenia by itself was not significantly related to PF due to the high proportion of older participants. In contrast, Kirihara et al. reported that a greater VATA and less skeletal muscle were associated with PF after PD (2). Using the VATA/SMI evaluation, severe obesity and sarcopenia are extracted rather than a simple assessment of VATA and SMI. The VATA/SMI is simple and easy to calculate as well as provides insight into how to approach nutrition in patients following surgery and provide an early rehabilitation program in patients with a high-VATA/SMI. Patients with a high-VATA/SMI were susceptible to postoperative complications in our study. These findings emphasize the importance of the assessment and potential treatment of a high-VATA/SMI or an imbalance of visceral adipose and skeletal muscle in patients with hepatobiliary cancer who are scheduled for potentially curative surgery.

More abundant visceral adipose tissue was detected, while more intraoperative bleeding and longer operation time were reported $(19,20)$. In agreement with these observations, groups with elevated VATA/SMI levels were associated with massive intraoperative bleeding and longer operative time
Table II. Multivariate logistic analysis of risk factors for pancreatic fistula development in patients who underwent pancreaticoduodenectomy.

\begin{tabular}{lccc}
\hline Variables & HR & $95 \%$ CI & $p$-Value \\
\hline BMI $\geq 25\left(\mathrm{~kg} / \mathrm{m}^{2}\right)$ & 2.344 & $0.643-8.545$ & 0.197 \\
VATA $/ \mathrm{SMI} \geq 2.0$ & $\mathbf{5 . 3 5 3}$ & $\mathbf{1 . 5 3 4 - 1 8 . 6 8 0}$ & $\mathbf{0 . 0 0 9}$ \\
Pancreatic duct diameter $\leq 3(\mathrm{~mm})$ & $\mathbf{6 . 5 8 0}$ & $\mathbf{1 . 9 0 6 - 2 2 . 7 1 7}$ & $\mathbf{0 . 0 0 3}$ \\
Pancreatic texture (soft) & 0.628 & $0.167-2.362$ & 0.491 \\
Drain Amy on POD1 $\geq 5,000(\mathrm{U} / \mathrm{L})$ & $\mathbf{4 . 9 1 0}$ & $\mathbf{1 . 1 4 4 - 2 1 . 0 6 5}$ & $\mathbf{0 . 0 3 2}$ \\
\hline
\end{tabular}

Amy: Amylase; BMI: body mass index; CI: confident incidence; HR: hazard ratio; POD: postoperative day; SMI: skeletal muscle index; VATA: visceral adipose tissue area. Variables in bold are statistically significant $(p<0.05)$.

compared with groups with low-VATA/SMI. The loss of skeletal muscle along with increased adipose tissue promotes the production of pro-inflammatory adipokines, such as leptin, tumour necrosis factor- $\alpha$, interleukin (IL)-1, and IL$6(21,22)$. These data suggest that higher amount of visceral adipose tissue would not only interfere with surgical recovery by promoting the excessive production of proinflammatory cytokines, but also suppress the immune system. However, Goujoux et al. reported that there were no correlations with postoperative complications and body composition, as indicated by BMI and VATA (23). Further investigations of this underlying mechanism are necessary. 
Table III. Comparison of clinicopathological variables between patients with low and high visceral adipose tissue area/skeletal muscle index.

\begin{tabular}{|c|c|c|c|}
\hline Variables & Low-VATA/SMI $(\mathrm{n}=47)$ & High-VATA/SMI (n=52) & $p$-Value \\
\hline Age (years) & $72.0(39-86)$ & $73.0(47-86)$ & 0.749 \\
\hline Gender, male/female & $25 / 22$ & $44 / 8$ & 0.001 \\
\hline BMI $\left(\mathrm{kg} / \mathrm{m}^{2}\right)$ & $20.7(16.2-29.6)$ & $23.0(17.5-33.5)$ & $<0.001$ \\
\hline Diabetes mellitus & $8(17.0 \%)$ & $16(30.8 \%)$ & 0.111 \\
\hline Hypertension & $16(34.0 \%)$ & $33(63.5 \%)$ & 0.003 \\
\hline Smoking habit & $19(40.4 \%)$ & $34(65.4 \%)$ & 0.013 \\
\hline Alcohol abuse & $12(25.5 \%)$ & $31(59.6 \%)$ & 0.001 \\
\hline Preoperative biliary drainage & $13(27.7 \%)$ & $23(44.2 \%)$ & 0.087 \\
\hline WBC $(/ \mu \mathrm{l})$ & $5730(2860-12200)$ & $5515(3600-9500)$ & 0.537 \\
\hline Neut $(\%)$ & $57.6(17-93)$ & $59.3(34.9-88)$ & 0.958 \\
\hline Lymph $(\%)$ & $30.0(4-64)$ & $27.4(8-48)$ & 0.916 \\
\hline T-Bil (mg/dl) & $0.7(0.2-13.8)$ & $0.8(0.3-5.5)$ & 0.308 \\
\hline $\mathrm{Alb}(\mathrm{mg} / \mathrm{dl})$ & $3.8(3.0-4.7)$ & $3.7(2.8-4.4)$ & 0.858 \\
\hline $\mathrm{CRP}(\mathrm{mg} / \mathrm{dl})$ & $0.2(0-5.2)$ & $0.3(0.1-8.3)$ & 0.304 \\
\hline $\operatorname{SMI}\left(\mathrm{cm}^{2} / \mathrm{m}^{2}\right)$ & $43.3(29.7-59.1)$ & $44.7(30.4-45.9)$ & 0.277 \\
\hline $\operatorname{VATA}\left(\mathrm{cm}^{2}\right)$ & $47.7(3.8-101.7)$ & $141.8(67.4-391.9)$ & $<0.001$ \\
\hline SATA $\left(\mathrm{cm}^{2}\right)$ & $82.9(4.5-245)$ & $108.3(11.2-200.6)$ & $<0.001$ \\
\hline Operation time (min) & $483(353-755)$ & $521(355-767)$ & 0.002 \\
\hline Bleeding volume (ml) & $580(108-2638)$ & $978(248-6588)$ & 0.002 \\
\hline Major venous resection & $8(17.0 \%)$ & $15(28.8 \%)$ & 0.164 \\
\hline Pancreatic adenocarcinoma & $31(66.0 \%)$ & $28(53.8 \%)$ & 0.220 \\
\hline Pancreatic diameter $\leq 3(\mathrm{~mm})$ & $16(34.0 \%)$ & $17(32.7 \%)$ & 0.827 \\
\hline Pancreatic texture (soft) & $20(42.6 \%)$ & $23(44.2 \%)$ & 0.629 \\
\hline Drain Amy on POD1(U/L) & $143(6-71860)$ & $732(7-97530)$ & 0.060 \\
\hline PF $($ Grade B/C) & $7(14.9 \%)$ & $23(44.2 \%)$ & 0.002 \\
\hline
\end{tabular}

Alb: Albumin; Amy: amylase; BMI: body mass index; CRP: C reactive protein; Lymph: lymphocyte; PF: pancreatic fistula; POD: postoperative day; Neut: neutrophil; SATA: subcutaneous adipose tissue area; SMI: skeletal muscle index; T-bil: total bilirubin; WBC: white blood cell; VATA: visceral adipose tissue area. A VATA/SMI $<2.0$ was defined as a low-VATA/SMI, and a VATA/SMI $\geq 2.0$ was defined as a high-VATA/SMI. Continuous variables are expressed as median (range). Qualitative variables are expressed as a number (\%). Variables in bold are statistically significant $(p<0.05)$.

Pancreatic duct diameter is a well-documented risk factor for PF development after PD $(3,24,25)$. Pratt et al. reported that a smaller pancreatic duct is an increased risk factor for PF development (26). Additionally, soft pancreatic tissue is a well-known risk factor for PF development and is likely due to the fragility of the parenchyma and a narrow main pancreatic duct given the difficulty in suturing following PF development after PD (8). Pancreatic duct and texture were frequently observed to influence preoperative pancreatitis due to tumor obstruction, which resulted in the widening of the pancreatic duct and hardening of its texture. This suggests that preoperative assessment with endoscopic ultrasonographyelastography also provides important information for selecting surgical intervention (27). Evaluating the combined VATA/SMI ratio and pancreatic fibrosis by EUS-elastography is important to predict PF after PD.

Some reports have proposed that the high drain Amy concentration is not related with PF occurrence $(28,29)$. Conversely, many reports have shown that the Amy value in drainage was important for predicting PF development after
$\mathrm{PD}(6,15,30)$. In our study, drain Amy concentration $\geq 5000$ $\mathrm{U} / \mathrm{L}$ on POD1 was an independent risk factor for PF development. Kawai et al. reported that intraoperative bleeding $>1000 \mathrm{ml}$, a soft pancreas, and drain Amy on POD1 $>4000 \mathrm{U} / \mathrm{L}$ are significant predictive factors for PF development (6). Meanwhile, Molinari et al. reported that the drain Amy on POD1 $\geq 5000 \mathrm{U} / \mathrm{L}$ was the only significant factor for PF development (15). Indeed, while the pancreatic diameter and postoperative drain Amy level are important risk factors for PF development after PD, no measure can be assessed preoperatively. Preoperative measures would help to identify patients who are at a high-risk for $\mathrm{PF}$ development. Patients can then act to enhance their nutrition and level of activity in preparation for their operation.

This study has some limitations. We included patients not only with pancreatic duct adenocarcinoma, but also with extrahepatic biliary malignancies. Therefore, we could not provide long-term outcomes. In addition, this is a retrospective non-randomized study from a single institution with a relatively small number of patients. 
In conclusion, the preoperative evaluation of muscle and adipose volume was effective in predicting PF development after PD. This assessment would be useful in determining individual surgical procedures and provide perioperative management. We suggest that managing the level of visceral adipose tissue or skeletal muscle will help prevent PF development.

\section{Conflicts of Interest}

The Authors declare no conflicts of interest.

\section{Acknowledgements}

This manuscript has not been published and is not under consideration for publication elsewhere.

\section{References}

1 Kawai M, Tani M, Hirono S, Ina S, Miyazawa M and Yamaue $\mathrm{H}$ : How do we predict the clinically relevant pancreatic fistula after pancreaticoduodenectomy? An analysis in 244 consecutive patients. World J Surg 33(12): 2670-2678, 2009.

2 Kirihara Y, Takahashi N, Hashimoto Y, Sclabas GM, Khan S, Moriya T, Sakagami J, Huebner M, Sarr MG and Farnell MB: Prediction of pancreatic anastomotic failure after pancreatoduodenectomy: the use of preoperative, quantitative computed tomography to measure remnant pancreatic volume and body composition. Ann Surg 257(3): 512-519, 2013.

3 Fu SJ, Shen SL, Li SQ, Hu WJ, Hua YP, Kuang M, Liang LJ and Peng BG: Risk factors and outcomes of postoperative pancreatic fistula after pancreatico-duodenectomy: an audit of 532 consecutive cases. BMC Surg 15: 34, 2015.

4 Fuks D, Piessen G, Huet E, Tavernier M, Zerbib P, Michot F, Scotte M, Triboulet JP, Mariette C, Chiche L, Salame E, Segol $\mathrm{P}$, Pruvot FR, Mauvais F, Roman $\mathrm{H}$, Verhaeghe $\mathrm{P}$ and Regimbeau JM: Life-threatening postoperative pancreatic fistula (grade C) after pancreaticoduodenectomy: incidence, prognosis, and risk factors. Am J Surg 197(6): 702-709, 2009.

5 Bassi C, Dervenis C, Butturini G, Fingerhut A, Yeo C, Izbicki J, Neoptolemons J, Sarr M, Traverso W and Buchler M: Postoperative pancreatic fistula: an international study group (ISGPF) definition. Surgery 138(1): 8-13, 2005

6 Kawai M, Kondo S, Yamaue H, Wada K, Sano K, Motoi F, Unno M, Satoi S, Kwon AH, Hatori T, Yamamoto M, Matsumoto J, Murakami Y, Doi R, Ito M, Miyakawa S, Shinchi H, Natsugoe S, Nakagawara H, Ohta T and Takada T: Predictive risk factors for clinically relevant pancreatic fistula analyzed in 1,239 patients with pancreaticoduodenectomy: multicenter data collection as a project study of pancreatic surgery by the Japanese Society of Hepato-Biliary-Pancreatic Surgery. J Hepatobiliary Pancreat Sci 18(4): 601-608, 2001.

7 Lee SE, Jang JY, Lim CS, Kang MJ, Kim SH, Kim MA and Kim SW: Measurement of pancreatic fat by magnetic resonance imaging: predicting the occurrence of pancreatic fistula after pancreatoduodenectomy. Ann Surg 251(5): 932-936, 2010

8 Callery MP, Pratt WB, Kent TS, Chaikof EL and Vollmer CM Jr.: A prospectively validated clinical risk score accurately predicts pancreatic fistula after pancreatoduodenectomy. J Am Coll Surg 216(1): 1-14, 2010
9 Fukushima H, Yokoyama M, Nakanishi Y, Tobisu K and Koga F: Sarcopenia as a prognostic biomarker of advanced urothelial carcinoma. PLoS One 10(1): e0115895, 2015.

10 Pecorelli N, Carrara G, De Cobelli F, Cristel G, Damascelli A, Balzano G, Beretta L and BragaM: Effect of sarcopenia and visceral obesity on mortality and pancreatic fistula following pancreatic cancer surgery. Br J Surg 103(4): 434-442, 2016.

11 Fujiwara N, Nakagawa H, Kudo Y, Tateishi R, Taguri M, Watadani T, Nakagomi R, Kondo M, Nakatsuka T, Minami T, Sato M, Uchino K, Enooku K, Kondo Y, Asaoka Y, Tanaka Y, Ohtomo K, Shiina S and Koike K: Sarcopenia, intramuscular fat deposition, and visceral adiposity independently predict the outcomes of hepatocellular carcinoma. J Hepatol 63(1): 131-140, 2015.

12 Kaido T, Ogawa K, Fujimoto Y, Ogura Y, Hata K, Ito T, Tomiyama K, Yagi S, Mori A and Uemoto S: Impact of sarcopenia on survival in patients undergoing living donor liver transplantation. Am J Transplant 13(6): 1549-1556, 2013.

13 Valero V 3rd, Amini N, Spolverato G, Weiss MJ, Hirose K, Dagher NN, Wolfgang CL, Cameron AA, Philosophe B, Kamel IR and Pawlik TM: Sarcopenia adversely impacts postoperative complications following resection or transplantation in patients with primary liver tumors. J Gastrointest Surg 19(2): 272-281, 2015.

14 Englesbe MJ, Patel SP, He K, Lynch RJ, Schaubel DE, Harbaugh C, Holcombe SA, Wang SC, Segev DL and Sonnenday CJ: Sarcopenia and mortality after liver transplantation. J Am Coll Surg 211(2): 271-278, 2010.

15 Molinari E, Bassi C, Salvia R, Butturini G, Crippa S, Talamini G, Falconi $\mathrm{M}$ and Pederzoli P: Amylase value in drains after pancreatic resection as predictive factor of postoperative pancreatic fistula: results of a prospective study in 137 patients. Ann Surg 246(2): 281-287, 2007.

16 Mitsiopoulos N, Baumgartner RN, Heymsfield SB, Lyons W, Gallagher D and Ross R: Cadaver validation of skeletal muscle measurement by magnetic resonance imaging and computerized tomography. J Appl Physiol 85(1): 115-122, 1988.

17 Martin L, Birdsell L, Macdonald N, Reiman T, Clandinin MT, McCargar LJ, Murphy R, Ghosh S, Sawyer MB and Baracos VE: Cancer cachexia in the age of obesity: skeletal muscle depletion is a powerful prognostic factor, independent of body mass index. J Clin Oncol 31(12): 1539-1547, 2013.

18 Tranchart H, Gaujoux S, Rebours V, Vullierme MP, Dokmak S, Levy P, Couvelard A, Belghiti J and Sauvanet A: Preoperative CT scan helps to predict the occurrence of severe pancreatic fistula after pancreaticoduodenectomy. Ann Surg 256(1): 139145, 2012.

19 Yoshikawa K, Shimada M, Kurita N, Iwata T, Nishioka M, Morimoto S, Miyatani T, Komatsu M, Mikami C and Kashihara $\mathrm{H}$ : Visceral fat area is superior to body mass index as a predictive factor for risk with laparoscopy-assisted gastrectomy for gastric cancer. Surg Endosc 25(12): 3825-3830, 2011.

20 Watanabe J, Tatsumi K, Ota M, Suwa Y, Suzuki S, Watanabe A, Ishibe A, Watanabe K, Akiyama H, Ichikawa Y, Morita S and Endo I: The impact of visceral obesity on surgical outcomes of laparoscopic surgery for colon cancer. Int J Colorectal Dis 29(3): 343-351, 2014.

21 Tilg H, Moschen AR: Adipocytokines: mediators linking adipose tissue, inflammation and immunity. Nat Rev Immunol 6(10): 772-783, 2006 
22 Rega G, Kaun C, Demyanets S, Pfaffenberger S, Rychli K, Hohensinner PJ, Kastl SP, Speidl WS, Weiss TW, Breuss JM, Furnkranz A, Uhrin P, Zaujec J, Zilberfarb V, Frey M, Roehle R, Maurer G, Huber K and Wojta J: Vascular endothelial growth factor is induced by the inflammatory cytokines interleukin- 6 and oncostatin $\mathrm{m}$ in human adipose tissue in vitro and in murine adipose tissue in vivo. Arterioscler Thromb Vasc Biol 27(7): 1587-1595, 2007.

23 Gaujoux S, Torres J, Olson S, Winston C, Gonen M, Brennan MF, Klimstra DS, D'Angelica M, DeMatteo R, Fong Y, House M, Jarnagin W, Kurtz RC and Allen PJ: Impact of obesity and body fat distribution on survival after pancreaticoduodenectomy for pancreatic adenocarcinoma. Ann Surg Oncol 19(9): 29082916, 2012.

24 Braga M, Capretti G, Pecorelli N, Balzano G, Doglioni C, Ariotti R and Di Carlo V: A prognostic score to predict major complications after pancreaticoduodenectomy. Ann Surg 254(5): 702-708, 2011.

25 Topal B, Fieuws S, Aerts R, Weerts J, Feryn T, Roeyen G, Bertrand C, Hubert C, Janssens M and Closset J: Pancreaticojejunostomy versus pancreaticogastrostomy reconstruction after pancreaticoduodenectomy for pancreatic or periampullary tumours: a multicentre randomised trial. Lancet Oncol 14(7): 655-662, 2013.

26 Pratt WB, Callery MP, Vollmer CM Jr.: Risk prediction for development of pancreatic fistula using the ISGPF classification scheme. World J Surg 32(3): 419-428, 2008.
27 Itoh Y, Itoh A, Kawashima H, Ohno E, Nakamura Y, Hiramatsu T, Sugimoto H, Sumi H, Hayashi D, Kuwahara T, Morishima T, Funasaka K, Nakamura M, Miyahara R, Ohmiya N, Katano Y, Ishigami M, Goto $\mathrm{H}$ and Hirooka Y: Quantitative analysis of diagnosing pancreatic fibrosis using EUS-elastography (comparison with surgical specimens). J Gastroenterol 49(7): 1183-1192, 2014.

28 Shyr YM, Su CH, Wu CW, Lui WY: Does drainage fluid amylase reflect pancreatic leakage after pancreaticoduodenectomy? World J Surg 27(5): 606-610, 2003.

29 Reid-Lombardo KM, Farnell MB, Crippa S, Barnett M, Maupin G, Bassi C and Traverso LW: Pancreatic anastomotic leakage after pancreaticoduodenectomy in 1,507 patients: a report from the Pancreatic Anastomotic Leak Study Group. J Gastrointest Surg 11(11): 1451-1458, 2007.

30 Takeishi K, Maeda T, Yamashita Y, Tsujita E, Itoh S, Harimoto N, Ikegami T, Yoshizumi T, Shirabe K and Maehara Y: A cohort study for derivation and validation of early detection of pancreatic fistula after pancreaticoduodenectomy. J Gastrointest Surg 20(2): 385-391, 2016. 